\title{
Square pulsed thermography applied to thermal defaults characterization
}

\author{
by Stefan Datcu*, Laurent Ibos*, Yves Candau*
}

*Centre d'Etude et de Recherche en Thermique, Environnement et Systèmes, Université Paris XII Val de Marne, 61 avenue du Général De Gaulle, 94010 Créteil, France

\begin{abstract}
In this study, we extended the flash method to the more general situation of a finite time excitation of the sample in the presence of thermal losses. The objective is the identification of the diffusivity map of a polymer material sample plate that contains some structural defaults simulated on the rear side by artificial damages of cylindrical shape. A comparative analysis of the diffusivity values on the sound and the default areas may allow computing the default depth.
\end{abstract}

\section{Introduction}

Transient infrared temperature measurements can provide useful data for an accurate quantitative characterisation of plane systems. Impulse thermography is an active approach used to perform thermal characterization of materials.

The flash method [1] allows computing an apparent diffusivity map of inhomogeneous material by using a Dirac excitation. Used on the back face, the flash method was widely used in thermal metrology, relatively to front face excitation. The main drawback of this well-known method is the compromise between the flash intensity, the exposition time, the temperature increase of the sample and the penetration depth of the thermal wave.

A version of the flash method on front face, based on a various excitation time, is largely used in industry for CND purpose. Quantitatively, we notice some studies on the thickness quantification and diffusivity / effusivity estimation of coatings [2], depth and thermal resistance of some defaults located at the interface of two layers, [3]. Some experience optimisation aspects like the heating time [4] were also reached. These studies were carried out by considering that the sample has an insulated back face.

Our purpose is to extent the analysis of performances of front side flash method by considering the heat losses on the both front and back faces of a sample, in order to avoid systematic errors [4]. On the other side, we considered a finite excitation time, in order to better control the thermal wave penetration depth.

\section{1D transient temperature model and inverse problem}

We stand on the case of a 1D conductive transfer on a slab made on a homogeneous isotrope material. 


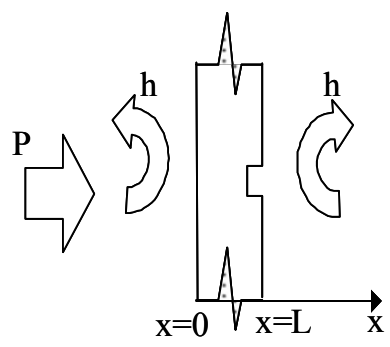

Figure 1: Schematics of the experimental procedure

The physical model corresponding to the studied configuration, presented in figure 1 , is given by:

$$
\begin{aligned}
& \frac{\partial^{2} \theta}{\partial x^{2}}=\frac{1}{a} \cdot \frac{\partial \theta}{\partial t}, \quad t=0, \quad \theta(x, 0)=0 \\
& x=0, \quad-k \cdot \frac{\partial \theta(0, t)}{\partial x}+h \cdot \theta(0, t)=f_{1}(t), \quad f_{1}(t)=\left\{\begin{array}{l}
P, t \leq t_{e} \\
0, t>t_{e}
\end{array}\right. \\
& x=L, \quad k \cdot \frac{\partial \theta(L, t)}{\partial x}+h \cdot \theta(L, t)=0 \\
& \theta(x, 0)=0
\end{aligned}
$$

where $\theta(x, t)$ is the sample temperature variation, $k$ is the thermal conductivity, $a$ is the thermal diffusivity, $h=h_{r}+h_{c}$ is the mean global thermal transfer coefficient, $P$ is the amplitude of the sample absorbed part of the excitation source power, $t_{e}$ is the excitation time and $L$ is the sample thickness. The radiative part $h_{r}$ of the transfer coefficient is almost constant during the heating and the cooling periods due to the weak correlation with the temperature variation [2]. It has been shown that the influence of the transfer coefficient $h$ on the diffusivity estimation is low [5], which allows us to consider the sample thermal losses amplitude on the rear as well as on the front side.

The integral transforms seems to be the most adapted methods to solve this problem [6]. The solution corresponding to the observation of the temperature response on the front side of the sample is given by the following relationship:

$$
\theta\left(0, t^{\prime}\right)=\frac{2 \cdot P \cdot L}{k} \cdot\left\{\left.\left(\sum_{n=1}^{\infty} \frac{\left(1-e^{-a \cdot b_{n}^{2} \cdot t}\right)}{\left(b_{n} \cdot L\right)^{2}+2 \cdot N B+N B^{2}}\right)\right|_{t \leq t_{e}}+\left.\left(\sum_{n=1}^{\infty} \frac{\left(e^{a \cdot b_{n}^{2} \cdot t_{e}}-1\right) \cdot e^{-a \cdot b_{n}^{2} \cdot t}}{\left(b_{n} \cdot L\right)^{2}+2 \cdot N B+N B^{2}}\right)\right|_{t>t_{e}}\right\}
$$

With $\tan \left(b_{n} \cdot L\right)=\frac{2 \cdot\left(b_{n} \cdot L\right) \cdot N B}{\left(b_{n} \cdot L\right)^{2}-N B^{2}}$

where $N B=\frac{h \cdot L}{k}$

is the Biot number. 
The inverse problem consist in the determination of the local diffusivity $a$ knowing the material thickness $L$, or the local thickness knowing the diffusivity from the measured temperature data $\theta$. This ill-posed problem can be solved by transforming it into a well posed approximate solution, a least square problem. Nevertheless, the problem is nonlinear and with low sensitivity coefficients, which means a high sensitivity to measurement errors. A sensitivity analysis performed (not presented here) showed that the sensitivity to the thickness is lower than the sensitivity to the diffusivity, which means that the diffusivity is better estimated than the thickness.

\section{Experimental set-up}

The acquisition of IR images was carried out by using a long wave focal plane uncooled micro-bolometers array digital IR camera Agema 570 Elite of FLIR Systems ${ }^{\circledR}$. The bundle "Researcher RT2000", including a PCMCIA card and software for thermal images acquisition, was used to acquire the infrared images on a PC-type computer. Some of the major technical specifications of the IR camera are listed in Table 1.

The excitation source is made by two $500 \mathrm{~W}$ halogen lamps. Shutters were positioned on the front of the lamps, falling down at the end of heating to stop any "after glow" heat from filament reaching the sample. Shutters were covered by an Aluminum film in order to minimize radiative exchanges. The measurements were carried out on a PVC sample of size of $170 \times 150 \times 5.25 \mathrm{~mm}$. Structural defaults were simulated on the rear side by drilling 6 artificial damages of cylindrical shape ranged on two lines. The back-drilled cylindrical holes defaults were of diameters $10 \mathrm{~mm}$, and $6 \mathrm{~mm}$ at depth $2 \mathrm{~mm}$, and $6 \mathrm{~mm}$ at depths $3 \mathrm{~mm}$. The sample was mounted vertically in the FOV of the camera. The front surface of the sample, facing the camera, was heated for $60 \mathrm{~s}$ and for $120 \mathrm{~s}$. The surface temperature distribution is registered at $1 \mathrm{~Hz}$. The object parameters imposed to the camera during acquisition are listed in table 2 .

Table 1. Technical specifications of the Agema 570 camera.

\begin{tabular}{|l|l|l|l|l|}
\hline $\begin{array}{l}\text { Field of } \\
\text { view }\end{array}$ & IFOV & $\begin{array}{l}\text { Spectral } \\
\text { range }\end{array}$ & Accuracy & Image size \\
\hline $24 \times 18^{\circ}$ & $1.3 \mathrm{mrad}$ & $7.5-13 \mu \mathrm{m}$ & $\begin{array}{l} \pm 2 \% \text { of range or } \\
\pm 2^{\circ} \mathrm{C}\end{array}$ & $\begin{array}{l}320 \mathrm{x} \quad 240 \\
\text { pixels }\end{array}$ \\
\hline
\end{tabular}

Table 2. Object parameters used for infrared images acquisition.

\begin{tabular}{|l|l|l|l|l|l|}
\hline $\begin{array}{l}\text { Relative } \\
\text { Humidity }\end{array}$ & Distance Camera-Object & $\begin{array}{l}\text { Ambient } \\
\text { Temperature }\end{array}$ & $\begin{array}{l}\text { Atmospheric } \\
\text { Temperature }\end{array}$ & $\varepsilon$ & $\tau$ \\
\hline $50 \%$ & $0.5 \mathrm{~m}$ & $20^{\circ} \mathrm{C}$ & $20^{\circ} \mathrm{C}$ & 1 & 1 \\
\hline
\end{tabular}

\section{Results}

The preliminary analysis of the temperature distribution on the sample front surface by amplitude allows to locate the defaults. The purpose is to give a representation of the slab thickness around the defaults region, therefore, to characterize the default shape, knowing the slab mean diffusivity. An infrared image of the PVC front side, taken 2 second after shutting down the infrared sources is presented on figure 2 . We notice the presence of the default footprint areas. 

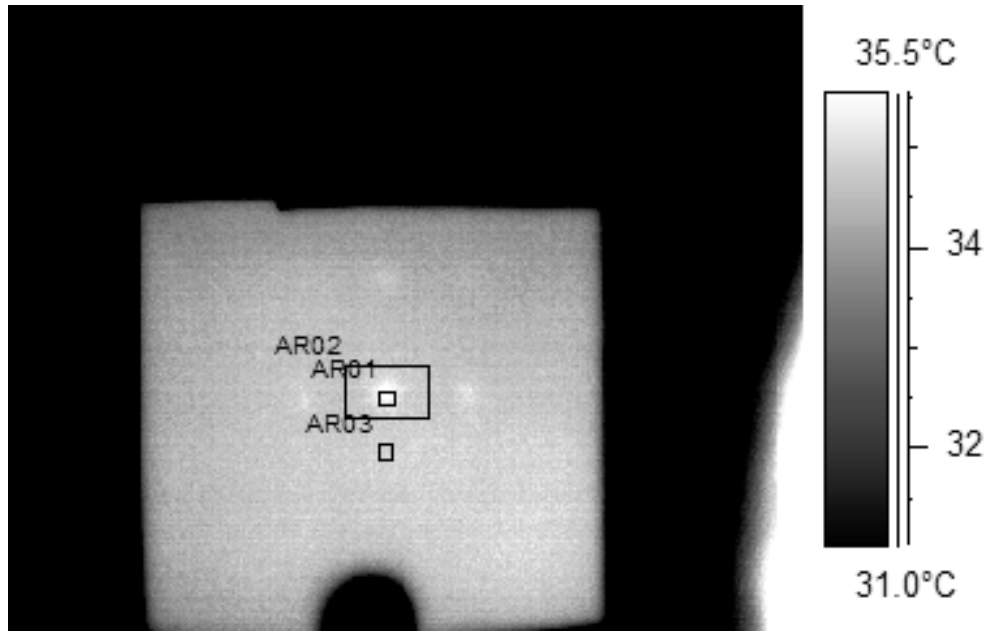

$31.0^{\circ} \mathrm{C}$

Figure 2: Front side PVC sample: default area (AR01) and sound area (AR03)

In figure 3, we show the measurement data and the least square fitting results on the sound (AR03) and the default (AR01) areas for the two exposition times: 60s and $120 \mathrm{~s}$. The estimation is performed on the mean temperature calculated on the two areas. In the presented case we have solved the well-posed problem for the diffusivity, knowing the slab thickness. The temperatures were calculated using a surface emissivity of 1 . The influence of the emissivity value on the parameter identification is not discussed here, but our future works will be focussed in this particular point.
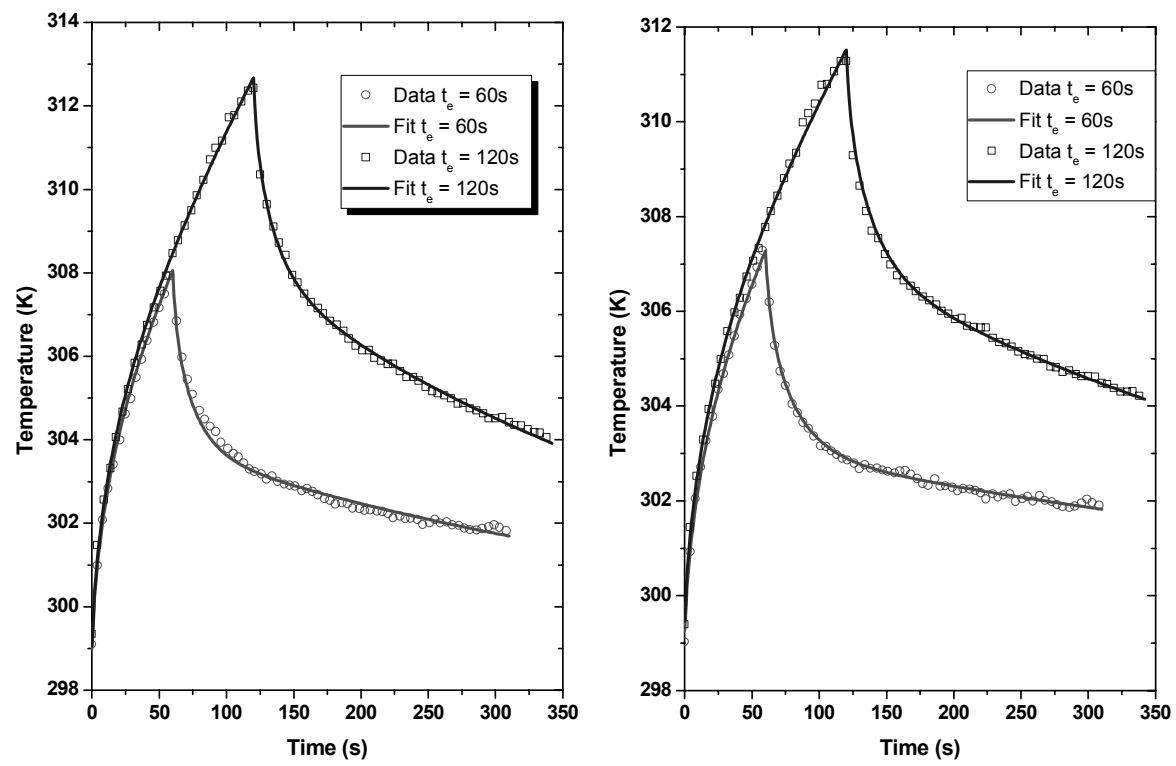

Figure 3: Front side PVC sample: left: default area (AR01); rigth: sound area (AR03) 
The estimated parameters obtained in these cases are presented in table 1. The values of $a$ in default area are greater than ones obtained in the sound region because the PVC plate thickness in the model is constant. So the $a$ values identified correspond to "apparent" diffusivity values. The diffusivity estimated value on the sound area was close to the reference value $\left(a_{r e f}=1.16 \cdot 10^{-7} \mathrm{~m}^{2} / \mathrm{s}\right)$ obtained by periodic method [7]. The estimated values of $a$ do not depend on the excitation time ( $\delta a / a \approx 8 \%$ ). On the contrary, the Biot number is dependent on the excitation time ( $\delta N B / N B \approx 30 \%$ ), probably because the $h$ value is changed. As expected a, low variation of $\underline{P}$ upon excitation time was noticed.

Table 1. Identification results.

\begin{tabular}{|l|l|l|l|l|l|l|}
\hline \multirow{2}{*}{$t_{e}$} & \multicolumn{4}{|l|}{ Sound area } & \multicolumn{2}{l|}{ Default area } \\
\cline { 2 - 7 } & $\underline{P}=2 \cdot P \cdot L / k$ & $N B$ & $a$ & $\underline{P}=2 \cdot P \cdot L / k$ & $N B$ & $a$ \\
\hline$(\mathrm{s})$ & $(\mathrm{K})$ & $(-)$ & $\cdot 10^{6} \mathrm{~m}^{2} / \mathrm{s}$ & $(\mathrm{K})$ & $(-)$ & $10^{6} \mathrm{~m}^{2} / \mathrm{s}$ \\
\hline 60 & 33.35 & 0.19 & 0.121 & 33.17 & 0.21 & 0.162 \\
\hline 120 & 35.44 & 0.25 & 0.131 & 36.42 & 0.26 & 0.176 \\
\hline
\end{tabular}

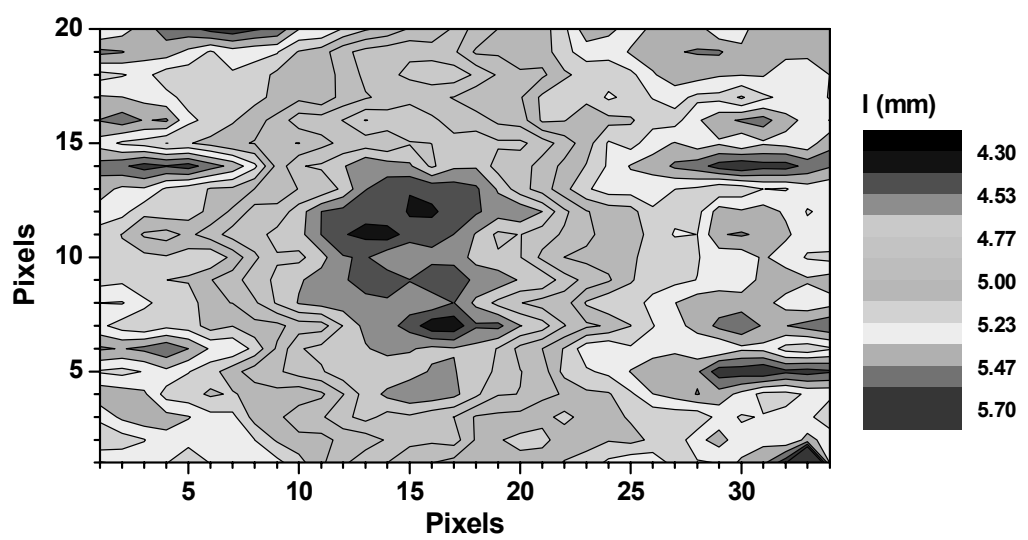

Figure 4: Contours of the depth as resulting from 1D model estimation in AR02 region; excitation time was 60 s

Considering 1D conduction transfer, we estimated the slab depth on the AR02 area, using the diffusivity reference value. The estimated depth contours are showed on the figure 4 , and the resulting depth slab map is presented on the figure 5 . We have found a estimated depth on the defaults center of $4.2 \mathrm{~mm}$ relatively to a measured $3.25 \mathrm{~mm}$ measured one. 


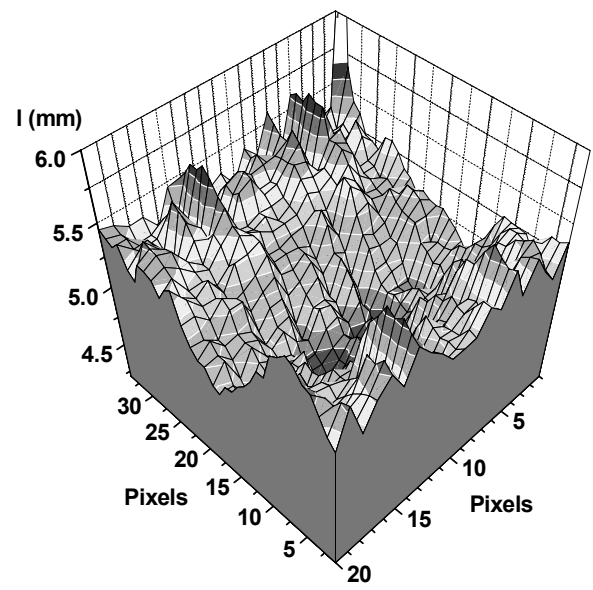

\section{Conclusions}

Figure 5: Sample depth estimation (AR02); te $=60 \mathrm{~s}$

Depth estimation corresponding uncertainties are about $60 \%$ which could explain the estimation error by a poorer sensitivity of the temperature to the depth. Also, a second cause could be the significance of the 3D transfers due to the default shape, that can be quantified by a $3 \mathrm{D}$ numerical modelisation.

\section{ACKNOWLEDGMENTS}

We want to thank especially $M$. Jean-Claude Frichet from the R\&D department of Electricité de France for the loan of the infrared camera.

\section{REFERENCE}

[1] W. J. Parker and al., "Flash method of determining thermal diffusivity, heat capacity and thermal conductivity", Journal Appl. Phys., vol 32, No 9, pp 16791684, 1961.

[2] J. C. Krapez and al., "Méthode flash en face avant. Optimisation de l'expérience pour une monocouche et un bicouche", Proceedings of SFT 2002 conference, pp 523-528, Ed. Elsevier, ISBN : 2-84299-375-6.

[3] D. Maillet and al., "Méthodes intégrales et contrôle non destructif par thermographie infrarouge stimulée", Rev Gén Therm (1996) 35, pp 14-27.

[4] A. Degiovanni, "Diffusivité par méthode flash", Rev Gén Therm (1977) 185, pp 420-442.

[5] M. Rebay, "Contribution à l'étude de la convection force en régime variable; application à la mesure de coefficients d'échange par méthode impulsionnelle", PhD Thesis, University of Reims, 1998.

[6] D. Tsacalos, "Résolution des problemes de thermocinétique linéaire par la méthode des transformations intégrales finie", Rev. Gén. Therm. (1979) 214, pp 609-619.

[7] E. Tang-Kwor, "Contribution au développement de méthodes périodiques de mesure de propriétés thermophysiques des matériaux opaques", PhD Thesis University Paris XII, 1998. 